\title{
Keanekaragaman Anggrek (Orchidaceae) di Taman Wisata Alam Sorong, Kota Sorong, Papua Barat
}

\author{
REZA SAPUTRA*, DJEFRY TIBALIA, FAJAR DARWIS, AKBAR SUMIRTO \\ Balai Besar Konservasi Sumber Daya Alam (BBKSDA) Papua Barat, Kementerian Lingkungan Hidup dan Kehutanan, Indonesia
}

Diterima: 21 September 2018 - Disetujui: 20 Oktober 2018

(C) 2018 Jurusan Biologi FMIPA Universitas Cenderawasih

\begin{abstract}
Orchid diversity studies have been conducted at the Sorong Nature Park, Sorong City, West Papua. There are 84 collection numbers consisting of 69 epiphytic orchids, 14 terrestrial orchids, and 1 holomycotrophic orchid. This number belongs to 34 genera and 84 species, which are native species with at least 36 endemic species. Dendrobium, Bulbophyllum, and Taeniophyllum are the three genera with the highest numbers of species.
\end{abstract}

Key words: Orchid, Diversity, Sorong National Park, West Papua.

\section{PENDAHULUAN}

New Guinea merupakan salah satu kawasan yang kaya akan diversitas anggrek (Millar, 1999). Sampai saat ini tercatat sekitar 2.869 spesies anggrek berasal dari New Guinea (11\% dari total anggrek di dunia) (Ormerod, 2017), dengan tingkat endemisitas mencapai 95\% (Schuiteman et al., 2001 - 2010). Berdasarkan Vollering et al. (2016), pengkoleksian anggrek yang berasal dari New Guinea bagian barat (Provinsi Papua dan Papua Barat, Indonesia) masih tergolong sedikit jika dibandingkan dengan New Guinea bagian timur (Papua Nugini) sebagaimana tumbuhan pada umumnya (Takeuchi, 2006; Schuiteman \& de Vogel, 2007). Pernyataan tersebut juga didukung oleh Ormerod (2014), yang menyatakan masih terdapat banyak spesies anggrek Papua yang belum diketahui. Lebih lanjut, pencatatan anggrek-anggrek yang ada di Papua harus segera dilakukan. Hal tersebut dikarenakan Papua

\footnotetext{
* Alamat korespondensi:

Balai Besar KSDA Papua Barat, Jln. Raya Klamono Km. 16 Kotak Pos: 1053 Sorong, Papua Barat 98415. Telp. 0951321986. E-mail: reza.saputraa21@gmail.com
}

menjadi salah satu daerah dengan potensi kerusakan hutan berupa pemekaran wilayah dan pembentukan kabupaten baru yang cukup mengancam keberadaan jenis anggrek (Agustini et al., 2012).

Salah satu kawasan dengan pengkoleksian anggrek yang masih sedikit adalah Kota Sorong, Papua Barat (Vollering et al., 2016). Satu-satunya kawasan konservasi di Kota Sorong yang masih terjaga ekosistemnya yakni Taman Wista Alam (TWA) Sorong (Alam et al., 2016). Secara administratif, Taman Wisata Alam Sorong berada di Kelurahan Klablim, Kota Sorong, Provinsi Papua Barat. Secara geografis, kawasan ini terletak pada koordinat $131^{\circ} 21^{\prime}$ BT sampai $131^{\circ} 19^{\prime} \mathrm{BT}$ dan $0^{\circ} 51$ LS sampai $0^{\circ} 58^{\prime}$ LS. Berdasarkan pembagian wilayah pengelolaan Hutan dan Kawasan Konservasi Sumber Daya Alam, TWA Sorong berada di wilayah kerja Balai Besar KSDA Papua Barat Bidang Wilayah I Sorong Seksi Konservasi Wilayah II Teminabuan. Luas kawasan TWA Sorong sekitar 945,9 Ha berdasarkan Surat Keputusan Menteri Pertanian Nomor 397/Kpts/Um/5/1981 tanggal 7 Mei 1981.

Penelitian terkait anggrek di Taman Wisata Alam Sorong pernah dilakukan sebelumnya oleh Ponisri et al. (2012). Penelitian berhasil merekam 
sebanyak 14 jenis anggrek yang ada di TWA Sorong. Namun, penelitian tersebut masih terbatas oleh metode dan plot yang digunakan. Sehingga perlu dilakukan penelitian tambahan untuk merepresentasikan jenis-jenis anggrek di Taman Wisata Alam Sorong. Penelitian ini bertujuan untuk menginventarisasi jenis-jenis anggrek alam yang hidup di Taman Wisata Alam Sorong.

\section{METODE PENELITIAN}

Penelitian keanekaragaman jenis anggrek dilakukan di Taman Wisata Alam Sorong dari tanggal 5 Mei - 27 Juni 2018. Penelitian mencakup seluruh blok kawasan TWA Sorong, yakni blok khusus, blok pemanfaatan, blok rehabilitasi, dan blok perlindungan. Pengambilan sampel dilakukan dengan metode Visual Encounter Survey (VES) dengan batasan sampel yang diambil ialah tumbuhan anggrek yang sedang berbunga atau yang memiliki karakter kunci identifikasi. Selain itu dilakukan juga metode wawancara dengan warga sekitar dan eksplorasi untuk mencari anggrek hasil wawancara.

Anggrek yang ditemukan diambil foto habitus, daun, dan perbungaan terlebih dahulu untuk dokumentasi dan proses identifikasi. Selanjutnya

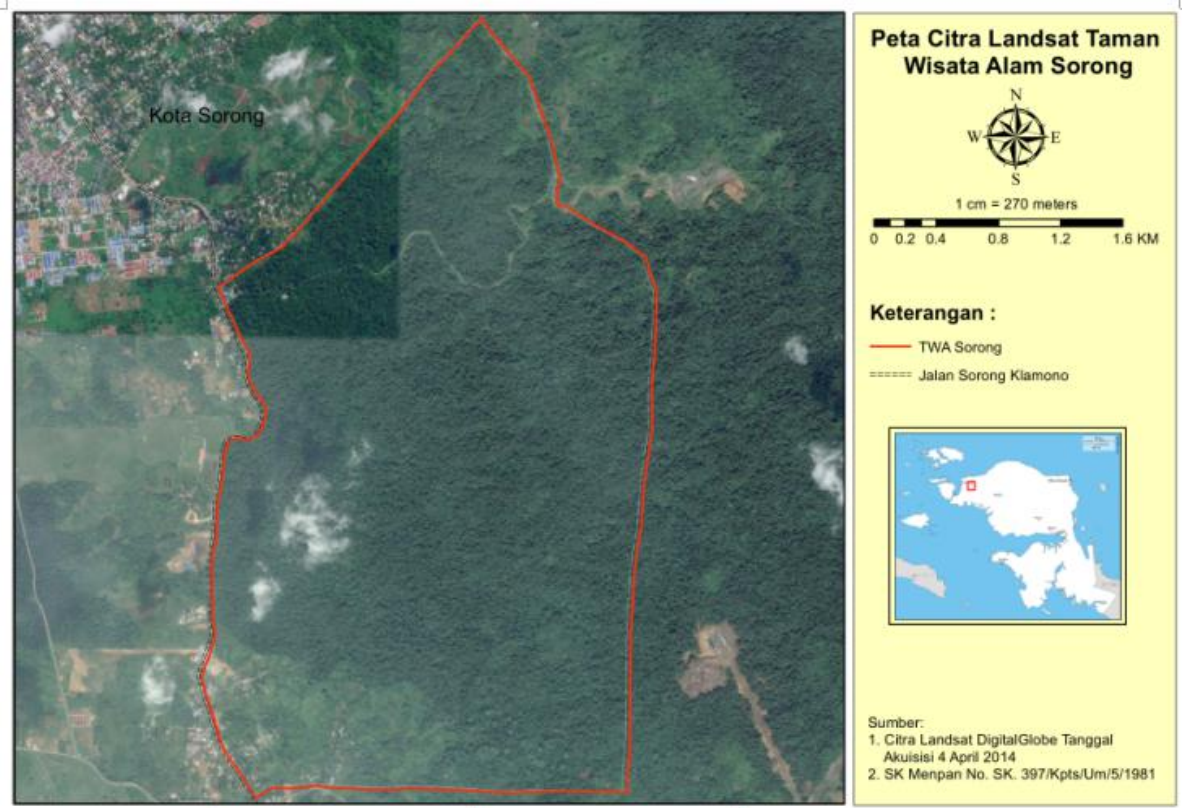

Gambar 1. Peta Citra Landsat Taman Wisata Alam Sorong, Papua Barat, sebagai tempat lokasi penelitian. koleksi hidup dibawa menggunakan kantong sampel untuk anggrek epifit, untuk anggrek teresterial dan holomikotropik dimasukan ke dalam plastik beserta substratnya. Setelah sampai di basecamp bunga anggrek diawetkan secara basah menggunakan alkohol 70\%. Koleksi hidup anggrek epifit ditempelkan pada pohon dengan menggunakan media paku sarang burung (Asplenium nidus L.) dan untuk anggrek teresterial menggunakan media tanah. Sedangkan untuk anggrek holomikotropik tidak dibuat koleksi hidup karena memiliki daur hidup yang singkat (cepat mati). Sampel anggrek kemudian diidentifikasi menggunakan buku Orchids of Papua New Guinea (Millar, 1999), Lowland Orchids of Papua New Guinea (O' Byrne, 1994), A Guide to Dendrobium of New Guinea (Schuiteman, 2013), dan Orchids of Indonesia (Handoyo, 2010), serta bantuan dari para pakar anggrek.

\section{HASIL DAN PEMBAHASAN}

Sebanyak 84 spesies anggrek yang tergolong ke dalam 34 genus ditemukan di Taman Wisata Alam (TWA) Sorong, Papua Barat. Terdapat 69 anggrek epifit, 12 anggrek teresterial, dan 1 anggrek holomikotropik (Tabel 1).

Salah satu contoh anggrek dengan tipe hidup epifit ialah Taeniophyllum conoceras Schltr. (The Conic Horn Taeniophyllum), anggrek tanpa daun dengan bunga berwarna kuning. Anggrek ini memiliki ciri khas pada bagian taji dan rostellum yang berbentuk seperti tanduk (Schuiteman \& de Vogel, 2002). Berdasarkan pengamatan lapangan, waktu perbungaan anggrek ini cukup singkat, yakni hanya satu hari. $T$. conoceras ditemu-kan hidup menempel di pohon Agathis labillardierei pada bagian midstory/canopy layer dengan 
kelembapan sedang dan intensitas cahaya yang tinggi. Selain itu, Dendrobium insigne (Blume)

Tabel 1. Jenis-jenis anggrek yang ditemukan pada kawasan Taman Wisata Alam Sorong, Papua Barat.

\begin{tabular}{|c|c|c|c|c|c|c|c|}
\hline No & Jenis & Endemik & Habitus & No. & Jenis & Endemik & Habitus \\
\hline 1. & $\begin{array}{l}\text { Acriopsis liliifolia } \\
\text { (J.Koenig) Seidenf. }\end{array}$ & $x$ & Epifit & 31. & $\begin{array}{l}\text { Dendrobium dichrotropis } \\
\text { Schltr. }\end{array}$ & $\checkmark$ & Epifit \\
\hline 2. & $\begin{array}{l}\text { Agrostophyllum } \\
\text { grandiflorum Schltr. }\end{array}$ & $\checkmark$ & Epifit & 32. & $\begin{array}{l}\text { Dendrobium erosum } \\
\text { (Blume) Lindl. }\end{array}$ & $x$ & Epifit \\
\hline 3. & $\begin{array}{l}\text { Appendicula reflexa } \\
\text { Blume }\end{array}$ & $x$ & Epifit & 33. & $\begin{array}{l}\text { Dendrobium falcipetalum } \\
\text { Schltr. }\end{array}$ & $\checkmark$ & Epifit \\
\hline 4. & $\begin{array}{l}\text { Bulbophyllum aff. } \\
\text { guttatum Schltr. }\end{array}$ & $\checkmark$ & Epifit & 34. & $\begin{array}{l}\text { Dendrobium funiforme } \\
\text { Blume }\end{array}$ & $x$ & Epifit \\
\hline 5. & $\begin{array}{l}\text { Bulbophyllum aff. serra } \\
\text { Schltr. }\end{array}$ & $\checkmark$ & Epifit & 35. & $\begin{array}{l}\text { Dendrobium goldfinchii } \\
\text { F.Muell. }\end{array}$ & $\checkmark$ & Epifit \\
\hline 6. & $\begin{array}{l}\text { Bulbophyllum aff. } \\
\text { pseudoserrulatum J.J.Sm. }\end{array}$ & $x$ & Epifit & 36. & $\begin{array}{l}\text { Dendrobium insigne } \\
\text { (Blume) Rchb.f. ex Miq. }\end{array}$ & $\checkmark$ & Epifit \\
\hline 7. & $\begin{array}{l}\text { Bulbophyllum appressum } \\
\text { Schltr. }\end{array}$ & $x$ & Epifit & 37. & $\begin{array}{l}\text { Dendrobium longicaule } \\
\text { J.J.Sm. }\end{array}$ & $\checkmark$ & Epifit \\
\hline 8. & $\begin{array}{l}\text { Bulbophyllum Sect. } \\
\text { Intervallate }\end{array}$ & - & Epifit & 38. & $\begin{array}{l}\text { Dendrobium macfarlanei } \\
\text { F.Muell. }\end{array}$ & $\checkmark$ & Epifit \\
\hline 9. & $\begin{array}{l}\text { Bulbophyllum } \\
\text { gracillimum (Rolfe) Rolfe }\end{array}$ & $\checkmark$ & Epifit & 39. & $\begin{array}{l}\text { Dendrobium } \\
\text { mirbelianum Gaudich. }\end{array}$ & $x$ & Epifit \\
\hline 10. & $\begin{array}{l}\text { Bulbophyllum } \\
\text { grandiflorum Blume }\end{array}$ & $x$ & Epifit & 40. & $\begin{array}{l}\text { Dendrobium odoardi } \\
\text { Kraenzl. }\end{array}$ & $\checkmark$ & Epifit \\
\hline 11. & $\begin{array}{l}\text { Bulbophyllum } \\
\text { infundibuliforme J.J.Sm. }\end{array}$ & $x$ & Epifit & 41. & $\begin{array}{l}\text { Dendrobium planum } \\
\text { J.J.Sm. }\end{array}$ & $x$ & Epifit \\
\hline 12. & $\begin{array}{l}\text { Bulbophyllum } \\
\text { macranthum Lindl. }\end{array}$ & $x$ & Epifit & 42. & $\begin{array}{l}\text { Dendrobium } \\
\text { platygastrium Rchb.f. }\end{array}$ & $x$ & Epifit \\
\hline 13. & $\begin{array}{l}\text { Bulbophyllum maxillare } \\
\text { (Lindl.) Rchb.f. }\end{array}$ & $x$ & Epifit & 43. & $\begin{array}{l}\text { Dendrobium poneroides } \\
\text { Schltr. }\end{array}$ & $\checkmark$ & Epifit \\
\hline 14. & $\begin{array}{l}\text { Bulbophyllum } \\
\text { membranaceum Teijsm. \& } \\
\text { Binn. }\end{array}$ & $x$ & Epifit & 44. & $\begin{array}{l}\text { Dendrobium smillieae } \\
\text { F.Muell. }\end{array}$ & $x$ & Epifit \\
\hline 15. & $\begin{array}{l}\text { Bulbophyllum nasica } \\
\text { Schltr. }\end{array}$ & $x$ & Epifit & 45. & Dendrobium sp. & - & Epifit \\
\hline 16. & $\begin{array}{l}\text { Bulbophyllum aff. } \\
\text { quinquelobum Schltr. }\end{array}$ & $\checkmark$ & Epifit & 46. & $\begin{array}{l}\text { Dendrobium } \\
\text { Grastidium }\end{array}$ & - & Epifit \\
\hline 17. & $\begin{array}{l}\text { Bulbophyllum sect. } \\
\text { Epicranthes }\end{array}$ & - & Epifit & 47. & $\begin{array}{l}\text { Dendrobium } \\
\text { Grastidium }\end{array}$ & - & Epifit \\
\hline 18. & $\begin{array}{l}\text { Bulbophyllum stabile } \\
\text { J.J.Sm. }\end{array}$ & $\checkmark$ & Epifit & 48. & $\begin{array}{l}\text { Dendrobium sect. } \\
\text { Crumenata }\end{array}$ & - & Epifit \\
\hline 19. & Coelogyne asperata Lindl. & $x$ & Epifit & 49. & $\begin{array}{l}\text { Dendrobium spectabile } \\
\text { (Blume) Miq }\end{array}$ & $\checkmark$ & Epifit \\
\hline 20. & $\begin{array}{l}\text { Dendrobium } \\
\text { acuminatissimum Lindl. } \\
\text { var. papuanum J.J. Sm. }\end{array}$ & $x$ & Epifit & 50. & $\begin{array}{l}\text { Dendrobium viridiflorum } \\
\text { F.M.Bailey }\end{array}$ & $\checkmark$ & Epifit \\
\hline 21. & Dendrobium sect. Fugacia & - & Epifit & 51. & Eria oligotricha Schltr. & $\checkmark$ & Epifit \\
\hline 22. & $\begin{array}{l}\text { Dendrobium aff. } \\
\text { macrostigma J.J.Sm. }\end{array}$ & $x$ & Epifit & 52. & Eria ramuana Schltr. & $\checkmark$ & Epifit \\
\hline 23. & $\begin{array}{l}\text { Dendrobium aff. } \\
\text { transversilobum J.J.Sm. }\end{array}$ & $\checkmark$ & Epifit & 53. & $\begin{array}{l}\text { Grammatophyllum } \\
\text { speciosum Blume }\end{array}$ & $x$ & Epifit \\
\hline 24. & $\begin{array}{l}\text { Dendrobium aff. } \\
\text { vandoides Schltr. }\end{array}$ & $x$ & Epifit & 54. & $\begin{array}{l}\text { Luisia tristis (G.Forst.) } \\
\text { Hook.f. }\end{array}$ & $x$ & Epifit \\
\hline 25. & $\begin{array}{l}\text { Dendrobium antennatum } \\
\text { Lindl. }\end{array}$ & $\checkmark$ & Epifit & 55. & Oberonia sp. & - & Epifit \\
\hline
\end{tabular}


Tabel 1. Lanjutan ......

\begin{tabular}{|c|c|c|c|c|c|c|c|}
\hline No & Jenis & Endemik & Habitus & No. & Jenis & Endemik & Habitus \\
\hline 26. & $\begin{array}{l}\text { Dendrobium bracteosum } \\
\text { Rchb.f. }\end{array}$ & $x$ & Epifit & 56. & $\begin{array}{l}\text { Oxystophyllum subsessile } \\
\text { (Schltr.) M.A.Clem. }\end{array}$ & $\checkmark$ & Epifit \\
\hline 27. & $\begin{array}{l}\text { Dendrobium } \\
\text { capituliflorum Rolfe }\end{array}$ & $\checkmark$ & Epifit & 57. & $\begin{array}{l}\text { Phalaenopsis amabilis } \\
\text { (L.) Blume }\end{array}$ & $x$ & Epifit \\
\hline 28. & $\begin{array}{l}\text { Dendrobium chrysotropis } \\
\text { Schltr. }\end{array}$ & $\checkmark$ & Epifit & 58. & $\begin{array}{l}\text { Pholidota imbricata } \\
\text { Lindl. }\end{array}$ & $x$ & Epifit \\
\hline 29. & $\begin{array}{l}\text { Dendrobium comatum } \\
\text { (Blume) Lindl. }\end{array}$ & $x$ & Epifit & 59. & Phreatia sp. & - & Epifit \\
\hline 30. & $\begin{array}{l}\text { Dendrobium conanthum } \\
\text { Schltr. }\end{array}$ & $\checkmark$ & Epifit & 60. & $\begin{array}{l}\text { Pomatocalpa marsupiale } \\
\text { (Kraenzl.) J.J.Sm. }\end{array}$ & $x$ & Epifit \\
\hline 61. & $\begin{array}{l}\text { Taeniophyllum aff. } \\
\text { kompsopus Schltr. }\end{array}$ & $\checkmark$ & Epifit & 73. & $\begin{array}{l}\text { Crepidium hydrophilum } \\
\text { (J.J.Sm.) Szlach. }\end{array}$ & $\checkmark$ & Terestrial \\
\hline 62. & $\begin{array}{l}\text { Taeniophyllum aff. } \\
\text { lamprorhizum Schltr. }\end{array}$ & $\checkmark$ & Epifit & 74. & $\begin{array}{l}\text { Dipodium pictum } \\
\text { (Lindl.) Rchb.f. }\end{array}$ & $x$ & Terestrial \\
\hline 63. & $\begin{array}{l}\text { Taeniophyllum conoceras } \\
\text { Schltr. }\end{array}$ & $\checkmark$ & Epifit & 75. & $\begin{array}{l}\text { Eulophia pulchra } \\
\text { (Thouars) Lindl. }\end{array}$ & $x$ & Terestrial \\
\hline 64. & $\begin{array}{l}\text { Taeniophyllum sect. } \\
\text { Rhynchanthera }\end{array}$ & $x$ & Epifit & 76. & Goodyera sp. & - & Terestrial \\
\hline 65. & $\begin{array}{l}\text { Tainia aff. trinervis } \\
\text { (Blume) Rchb.f. }\end{array}$ & $x$ & Epifit & 77. & $\begin{array}{l}\text { Hetaeria oblongifolia } \\
\text { Blume }\end{array}$ & $\checkmark$ & Terestrial \\
\hline 66. & Thelasis carinata Blume & $x$ & Epifit & 78. & $\begin{array}{l}\text { Macodes sanderiana } \\
\text { (Kraenzl.) Rolfe }\end{array}$ & $x$ & Terestrial \\
\hline 67. & $\begin{array}{l}\text { Thelasis micrantha } \\
\text { (Brongn.) J.J.Sm. }\end{array}$ & $x$ & Epifit & 79. & $\begin{array}{l}\text { Nervilia punctata } \\
\text { (Blume) Makino }\end{array}$ & $x$ & Terestrial \\
\hline 68. & $\begin{array}{l}\text { Thrixspermum collinum } \\
\text { Schltr. }\end{array}$ & $\checkmark$ & Epifit & 80. & $\begin{array}{l}\text { Neuwiedia veratrifolia } \\
\text { Blume }\end{array}$ & $x$ & Terestrial \\
\hline 69. & $\begin{array}{l}\text { Tuberolabium } \\
\text { rhopalorrhachis (Rchb.f.) } \\
\text { J.J.Wood }\end{array}$ & $x$ & Epifit & 81. & $\begin{array}{l}\text { Plocoglottis moluccana } \\
\text { Blume }\end{array}$ & $x$ & Terestrial \\
\hline 70. & Didymoplexis sp. & - & $\begin{array}{l}\text { Holo } \\
\text { mikotropik }\end{array}$ & 82. & $\begin{array}{l}\text { Spathoglottis papuana } \\
\text { F.M.Bailey }\end{array}$ & $\checkmark$ & Terestrial \\
\hline 71. & Apostasia wallichii R.Br. & $x$ & Terestrial & 83. & $\begin{array}{l}\text { Tropidia acuminata } \\
\text { Schltr. }\end{array}$ & $\checkmark$ & Terestrial \\
\hline 72. & $\begin{array}{l}\text { Corymborkis veratrifolia } \\
\text { (Reinw.) Blume }\end{array}$ & $x$ & Terestrial & 84. & Tropidia disticha Schltr. & $\checkmark$ & Terestrial \\
\hline
\end{tabular}

Ket.: $\mathbf{x}$ : tidak endemik, $\checkmark$ : endemik.

Rchb.f. ex Miq. juga ditemukan pada lingkungan yang sama. D. insigne merupakan salah satu jenis anggrek asli Papua dengan persebaran Maluku, Papua New Guinea, Queensland, sampai Kepulauan Solomon.

D. insigne memiliki ciri khas, yaitu tambahan pada bagian depan column dan daun yang terbagi menjadi 2 ukuran, meliputi sangat kecil dan cukup besar. Daun yang berukuran sangat kecil bersifat mudah gugur, dan terletak pada bagian ujung batang. Sedangkan daun yang berukuran cukup besar bersifat tahan lama, dan terletak pada bagian tengah dan pangkal batang (O’Byrne, 1994).
Pada jenis anggrek teresterial ditemukan Neuwiedia veratrifolia Blume dan Apostasia wallichii R.Br yang termasuk ke dalam subfamili Apostasioideae. Subfamili Apostasioideae merupakan satu dari lima anggota famili Orchidaceae yang memiliki karakter khas pada bunga, yaitu memiliki 2 hingga 3 anther abaksial (Endress, 2015). Jika dibandingkan dengan karakter anggrek pada umumnya yang memiliki 1 anther dan struktur bunga yang kompleks, Apostasia memiliki bunga sangat sederhana dengan karakter labelum yang menyerupai petal. Selain itu, Apostasia memiliki 2 anther fertil. Sedangkan Neuwiedia memiliki ciri khas yaitu memiliki 3 anther fertil. 
Oleh karena hal di atas dan didukung oleh data filogenetik (Kocyan et al., 2004), subfamili Apostasioideae dikategorikan menjadi kelompok anggrek yang paling dasar dalam famili Orchidaceae. Jenis anggrek ini merupakan jenis anggrek yang langka dan sangat sulit untuk dibudidayakan (Kocyan et al., 2004).

Pada kawasan New Guinea hanya terdapat 2 jenis anggrek dari subfamili Apostasioideae yaitu,

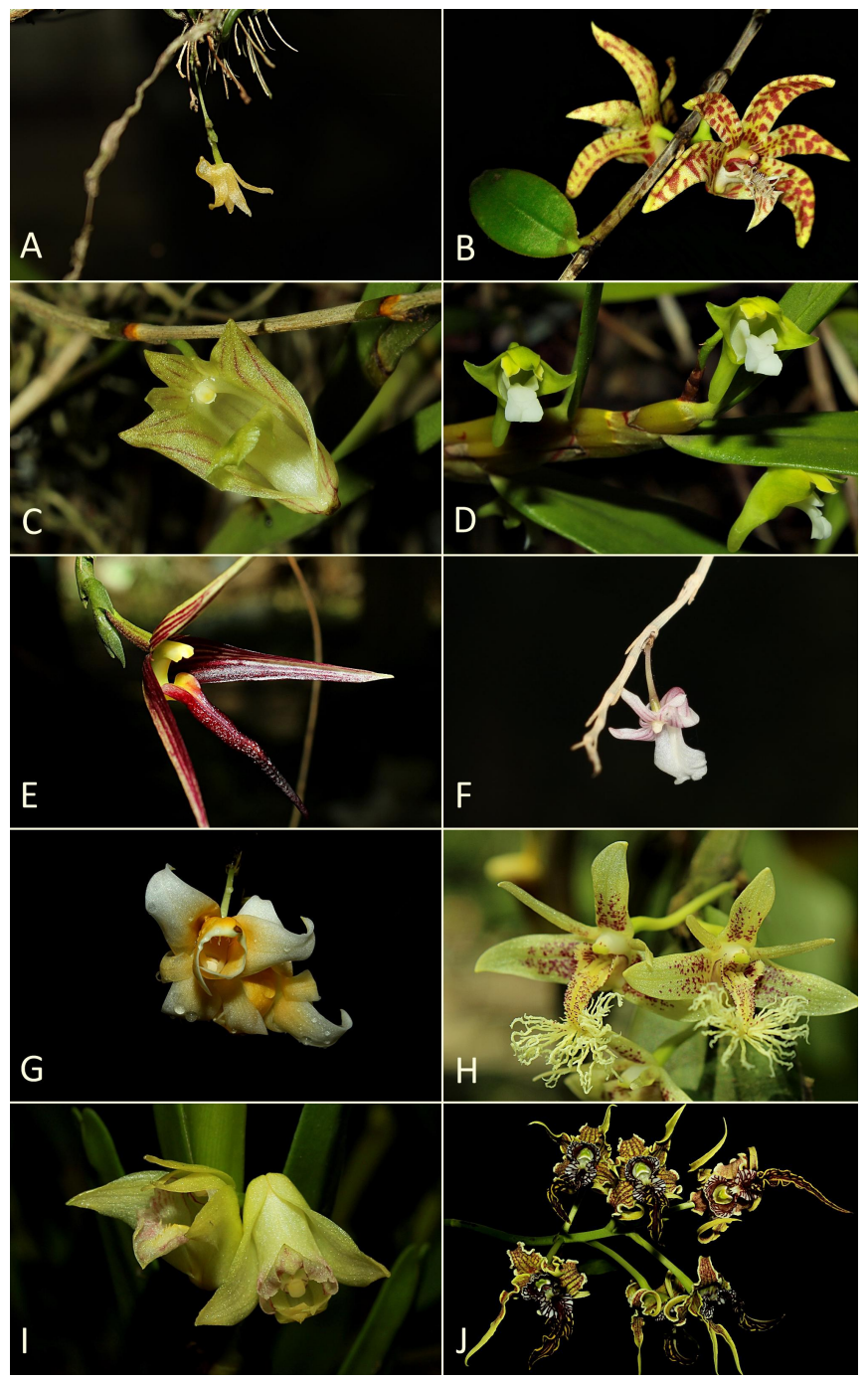

Gambar 2. Beberapa jenis anggrek di TWA Sorong.

A. Taeniophyllum conoceras, B. Dendrobium insigne, C. Dendrobium goldfinchii, D. Dendrobium viridiflorum, E. Bulbophyllum sp. Sect. Intervallate, F. Dendrobium macfarlanei, G. Dendrobium sp. Sect. Fugacia, H. Dendrobium comatum, I. Dendrobium planum, \& J. Dendrobium spectabile.
Neuwiedia veratrifolia dan Apostasia wallichii. Kedua anggrek tersebut dapat dijumpai pada blok pemanfaatan Taman Wisata Alam Sorong, Kota Sorong, Papua Barat. Sehingga Taman Wisata Alam Sorong sudah mewakili jenis anggrek dari subfamili Apostasioideae yang ada di Papua.

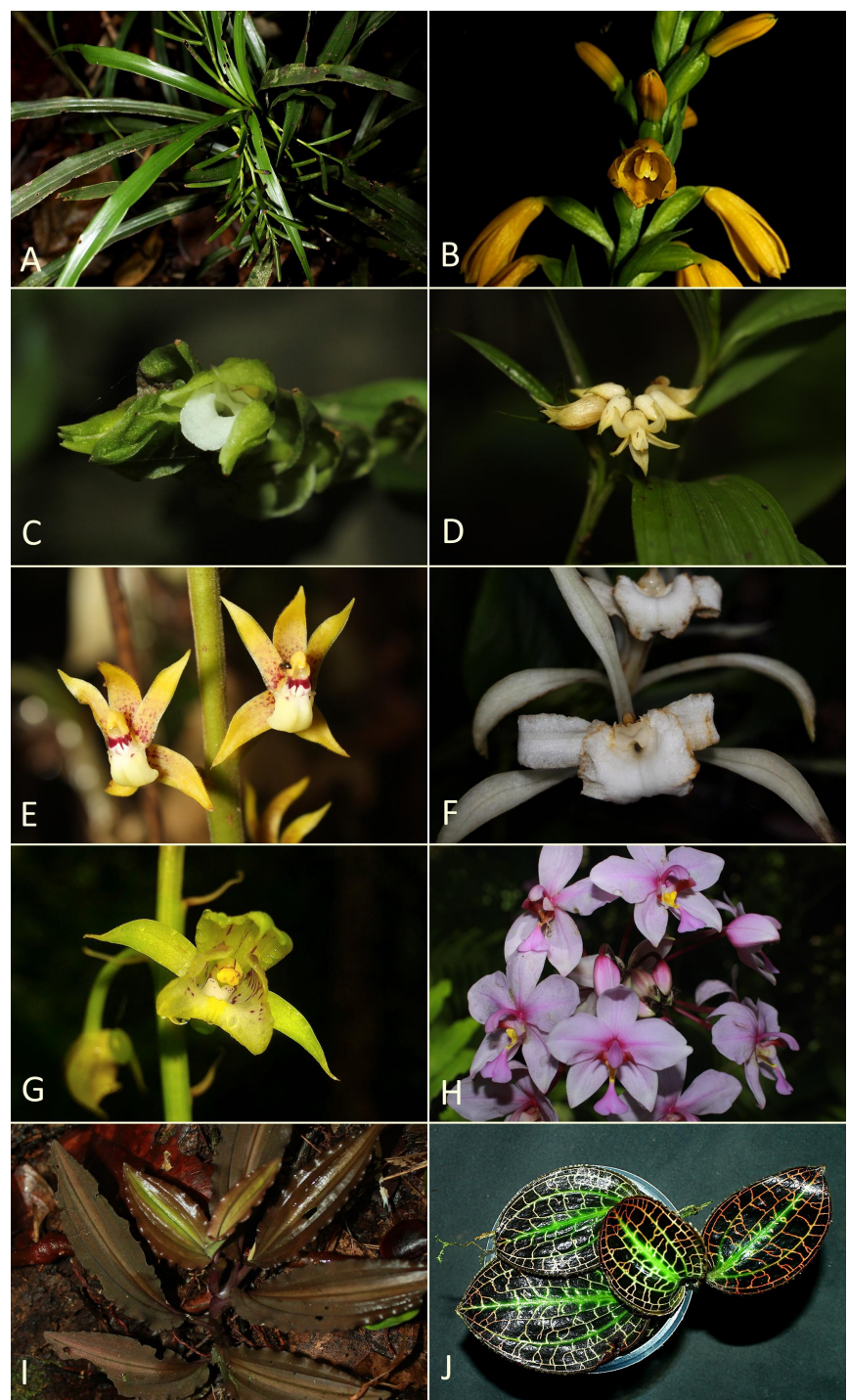

Gambar 3. Beberapa jenis anggrek terestrial di TWA Sorong. A. Apostasia wallichii, B. Neuwiedia veratrifolia, C. Tropidia disticha, D. Tropidia acuminata, E. Plocoglottis moluccana, F. Corymborkis veratrifolia, G. Eulophia pulchra, H. Spathoglottis papuana, I. Crepidium hydrophyllum, J. Macodes sanderiana. 


\section{KESIMPULAN}

Sebanyak 84 jenis anggrek ditemukan selama lebih kurang 2 bulan (5 Mei - 27 Juni 2018) survei inventariasasi di Taman Wisata Alam Sorong, Papua Barat. Jumlah tersebut terdiri dari 69 jenis anggrek epifit, 12 anggrek teresterial, dan 1 anggrek holomikotropik.

\section{DAFTAR PUSTAKA}

Agustini, V., S. Sufaati, Suharno. 2012. Keragaman jenis anggrek di Kawasan Hutan Distrik Oksibil, Pegunungan Bintang, Papua. Jurnal Biologi Papua. 4(1): 32-37.

Alam, S., D. Yansyah, dan A. Sumirto. 2016. Buku informasi kawasan konservasi Balai Besar KSDA Papua Barat. Balai Besar Konservasi Sumber Daya Alam Papua Barat. Sorong.

Endress, P.K. 2015. Development and evolution of extreme synorganization in angiosperm flowers and diversity: a comparison of Apocynaceae and Orchidaceae. Annals of Botany. 117(5): 749-767.

Handoyo, F. 2010. Orchids of Indonesia. Perhimpunan Anggrek Indonesia (PAI). Jakarta.

Kocyan, A., Y.-L. Qiu. P.K. Endress, and E. Conti. 2004. A phylogenetic analysis of Apostasioideae (Orchidaceae) based on ITS, trnL-F, and matK sequences. Plant Systematics and Evolution. 247: 203--213.
Millar, A. 1999. Orchids of Papua New Guinea. Crawford House Publishing Pty Ltd. Australia.

O'Byrne, P. 1994. Lowland orchids of Papua New Guinea. SNP Publisher.

Ormerod, P. 2014. Papuasian orchid studies 4. Malesian Orchid Journal 13: 37--68.

Ormerod, P. 2017. Checklist of Papuasian orchids. Nature \& Travel Books. Lismore.

Ponisri, Sutedjo, dan Sukartiningsih. 2012. Prospek konservasi jenis-jenis anggrek di Taman Wisata Alam Sorong, Papua Barat. Jurnal Kehutanan Tropika Humida. 5(1): 56-66.

Schuiteman, A. 2013. A guide to Dendrobium of New Guinea. Natural History Publication Sdn. Bhd. Borneo.

Schuiteman, A. and E.F. de Vogel. 2002. Flora Malesiana: Orchids of New Guinea vol. II. UNESCO Publishing, CDROM.

Schuiteman, A and E.F. de Vogel. 2007. Orchidaceae of Papua. In: Marshall AJ, Beehler BM (Eds). The Ecology of Papua. Part One. The Ecology of Indonesia Series VI. Periplus Ed.(HK) Ltd. Singapore.

Schuiteman, A., J.J. Vermeulen, and E.F. de Vogel. (2001-2010). Flora Malesiana: Orchids of New Guinea. Vol. I-VI. CDROM.

Takeuchi, W. 2006. Introduction to the flora of Papua. In: A.J. Marshall and B.M. Beehler. Editor. The Ecology of Papua. Periplus. Singapore. pp: 269-302.

Vollering, J., A. Schuiteman, E.F. de Vogel, R. van Vugt, and N. Raes. 2016. Phytogeography of New Guinean orchids: Patterns of species richness and turnover. Journal of Biogeography. 43: 204-214. 